\title{
Analysis of Factors of Construction Contract Transaction Cost Based on ISM Model ${ }^{* 1}$
}

\author{
LIU Hua ${ }^{1, a}$,WANG Yaoyao ${ }^{2, b}$ \\ ${ }^{1,2}$ School of Management,Xi'an University of Architecture and Technology,Xi'an 710055,China \\ aliuhualw@126.com, boeyaoyao@126.com
}

Keywords:Construction contract;transaction cost; Interpretive structural modeling method

\begin{abstract}
Based on ISM (Interpretative Structural Modeling) method, this paper stand in the perspective of construction enterprises,made a structured analysis on factors that affects the large-scale project construction contract transaction costs, and set up a clear hierarchy-structuring relation system. The results indicated that, in the construction contract transaction cost control should be use the contract cost-income ratio as the evaluation criterion, the other factors are controlled to improve the efficiency of the transaction.
\end{abstract}

\section{Introduction}

The construction industry has been a mainstay industries of China.In an increasingly competitive market circumstances, the level of project contract management can largely determine the smoothness of the execution of the construction project.In the construction market, the owners tend to dominate the contract, leading to the construction enterprise's profit margins are compressed,therefore, from the perspective of contract management,cost control is the help tool for construction enterprises in the harsh market environment running smoothly and even better.

Construction as a special deal, before and after the signing of the contract must spend a certain cost.Through the literature review and found that,transaction costs usually do the whole analysis from the perspective of the construction project,contract management theory on transaction costs is still in the initial stage of development. The introduction of transaction cost theory, from the contract process, the transaction dimension of the project construction contract cost to do a comprehensive analysis.In the process of construction contract transaction costs, the Interpretative Structural Modeling (ISM) method is introduced, which can transform many variables, complex relationship and unclear structure of construction contract transaction costs factors into intuitive, with well-structured relationship model structure, make it intuitive readability and informative.

\section{Interpretative Structural Modeling (ISM method) work}

Interpretative Structural Modeling Method,short for ISM method was developed by the United States N. Warfield John as a way to analyze the complex social and economic structure.Its main characteristic is that the complex system is decomposed into a number of subsystems by means of people's experience and knowledge as well as computer's help. The relationship between these factors will be arranged to form a matrix structure by calculating the reachable matrix and reordering, the system structure of factors to form a multilevel structure of the hierarchical model.

This model is based on qualitative analysis, which belongs to the structural model, especially for the many variables, the relationship between the structure factors of the system analysis is complex.

\footnotetext{
${ }^{1}$ Fund Project - Soft Science of Shaanxi Province “large engineering construction project contract management present situation analysis and countermeasure research of Shaanxi” (2013KRM43) 


\section{Establishment of Interpretative Structural Modeling(ISM method)for the influence factors of construction contract transaction cost.}

3.1 Factors affecting the cost of contract transaction.

The transaction cost factors in the literature.Li Changgu,Liu Zixian(2005)[1]believes in the establishment of the transaction cost functions, although the asset specificity, uncertainty and transaction frequency determine the final cost of the decisive role, in the daily transaction process, can not accurately measure their impact on the final transaction costs, therefore transaction costs can not be calculated by setting the variable.Ni Debing,Dai Chunai(2011)[2]regard relation as a implicit contract with exogenous explicit incentive problems, can not simply judge relationships is beneficial or detrimental to reduce the transaction costs.Sun Ying,Zhang Beibei(2011)[3] analyzed factors of energy services contract transaction costs.Based on the summary of previous studies, $\mathrm{Li}$ Huimin(2012)[4]explained the factors of construction project transaction costs from seven aspects, they are the scale of the project, project contracting mode, fierce bidding competition, the project area, the complexity and uncertainty of the project, project type, type of contract.Chris M. Wilson(2013)[5]introduced the incompleteness of contracts in the transaction costs, analysis the impact of transaction costs on the default.Queena K. Qian et.al(2013)[6]using game theory to analysis the real estate market, the transaction cost how to affect the building energy saving design product competition.It shows that the expected transaction costs of building energy-saving products affect the interests of developers, due to factors such as bounded rationality, opportunism and contract risk and asymmetric information limits.Ke Hong,Lv Tingzhu(2014)[7] believe that contract incompleteness have become the normal thing,leading to the low efficiency of the project contract, the high transaction costs of project contract and frequent engineering contract disputes.

The review of relevant literature, repeated research and discussion,standing on the construction enterprise view,determine the factors shown in Table 1 and the interaction between them of the following four types.

Table 1 Factors affecting the transaction cost of construction contract from construction enterprise angle

\begin{tabular}{|c|c|c|c|}
\hline Type & $\begin{array}{l}\text { Numbe } \\
r\end{array}$ & Factor & Effect of other factors \\
\hline \multirow{4}{*}{ enterprise itself } & $\mathrm{S}_{1}$ & financial strength & $\mathrm{S}_{7}$ \\
\hline & $\mathrm{S}_{2}$ & professional strength & $\mathrm{S}_{1}, \mathrm{~S}_{7}$ \\
\hline & $\mathrm{S}_{3}$ & contract cost-benefit ratio & - \\
\hline & $\mathrm{S}_{4}$ & the construction-in-progress quantity & $\mathrm{S}_{1}, \mathrm{~S}_{2}, \mathrm{~S}_{7}$ \\
\hline \multirow{5}{*}{ the objective factor } & $\mathrm{S}_{5}$ & contract incompleteness & $\mathrm{S}_{3}, \mathrm{~S}_{8}, \mathrm{~S}_{9}$ \\
\hline & $\mathrm{S}_{6}$ & information asymmetry & $\mathrm{S}_{3}, \mathrm{~S}_{8}, \mathrm{~S}_{12}, \mathrm{~S}_{13}$ \\
\hline & $\mathrm{S}_{7}$ & the asset specificity & $\mathrm{S}_{1}, \mathrm{~S}_{3}, \mathrm{~S}_{4}, \mathrm{~S}_{8}, \mathrm{~S}_{9}$ \\
\hline & $\mathrm{S}_{8}$ & the uncertainty of transaction & $\mathrm{S}_{3}, \mathrm{~S}_{4}, \mathrm{~S}_{7}, \mathrm{~S}_{9}$ \\
\hline & $\mathrm{S}_{9}$ & the transaction frequency & $\mathrm{S}_{3}, \mathrm{~S}_{4}, \mathrm{~S}_{7}$ \\
\hline \multirow{2}{*}{ the opponent factor } & $\mathrm{S}_{10}$ & opponent strength & $\mathrm{S}_{3} 、 \mathrm{~S}_{8}$ \\
\hline & $\mathrm{S}_{11}$ & opponent and owner's relation & $\mathrm{S}_{3}, \mathrm{~S}_{8}, \mathrm{~S}_{12}, \mathrm{~S}_{13}$ \\
\hline \multirow{2}{*}{$\begin{array}{l}\text { the environment } \\
\text { factor }\end{array}$} & $\mathrm{S}_{12}$ & Owner's strength and reputation & $\mathrm{S}_{1}, \mathrm{~S}_{3}, \mathrm{~S}_{6}, \mathrm{~S}_{13}$ \\
\hline & $\mathrm{S}_{13}$ & $\begin{array}{l}\text { the fairness of the competitive } \\
\text { environment }\end{array}$ & $\mathrm{S}_{3}, \mathrm{~S}_{8}, \mathrm{~S}_{9}, \mathrm{~S}_{12}$ \\
\hline
\end{tabular}

3.2 Establish an adjacency matrix

In order to analyze the influence of these factors, determine the direction of the relationship, when $\mathrm{i}=\mathrm{j}, \mathrm{Sij}=1$.According to table 1 ,Establish a system of ISM model, which indicates that the each factor affect the relationship of the adjacency matrix A. 
Table 2 adjacency matrix A

\begin{tabular}{cccccccccccccc}
\hline Factor & $\mathrm{S}_{1}$ & $\mathrm{~S}_{2}$ & $\mathrm{~S}_{3}$ & $\mathrm{~S}_{4}$ & $\mathrm{~S}_{5}$ & $\mathrm{~S}_{6}$ & $\mathrm{~S}_{7}$ & $\mathrm{~S}_{8}$ & $\mathrm{~S}_{9}$ & $\mathrm{~S}_{10}$ & $\mathrm{~S}_{11}$ & $\mathrm{~S}_{12}$ & $\mathrm{~S}_{13}$ \\
\hline $\mathrm{S}_{1}$ & 0 & 0 & 0 & 0 & 0 & 0 & 1 & 0 & 0 & 0 & 0 & 0 & 0 \\
$\mathrm{~S}_{2}$ & 1 & 0 & 0 & 0 & 0 & 0 & 1 & 0 & 0 & 0 & 0 & 0 & 0 \\
$\mathrm{~S}_{3}$ & 0 & 0 & 0 & 0 & 0 & 0 & 0 & 0 & 0 & 0 & 0 & 0 & 0 \\
$\mathrm{~S}_{4}$ & 1 & 1 & 0 & 0 & 0 & 0 & 1 & 0 & 0 & 0 & 0 & 0 & 0 \\
$\mathrm{~S}_{5}$ & 0 & 0 & 1 & 0 & 0 & 0 & 0 & 1 & 1 & 0 & 0 & 0 & 0 \\
$\mathrm{~S}_{6}$ & 0 & 0 & 1 & 0 & 0 & 0 & 0 & 1 & 0 & 0 & 0 & 1 & 1 \\
$\mathrm{~S}_{7}$ & 1 & 0 & 1 & 1 & 0 & 0 & 0 & 1 & 1 & 0 & 0 & 0 & 0 \\
$\mathrm{~S}_{8}$ & 0 & 0 & 1 & 1 & 0 & 0 & 1 & 0 & 1 & 0 & 0 & 0 & 0 \\
$\mathrm{~S}_{9}$ & 0 & 0 & 1 & 1 & 0 & 0 & 1 & 0 & 0 & 0 & 0 & 0 & 0 \\
$\mathrm{~S}_{10}$ & 0 & 0 & 1 & 0 & 0 & 0 & 0 & 1 & 0 & 0 & 0 & 0 & 0 \\
$\mathrm{~S}_{11}$ & 0 & 0 & 1 & 0 & 0 & 0 & 0 & 1 & 0 & 0 & 0 & 1 & 1 \\
$\mathrm{~S}_{12}$ & 1 & 0 & 1 & 0 & 0 & 1 & 0 & 0 & 0 & 0 & 0 & 0 & 1 \\
$\mathrm{~S}_{13}$ & 0 & 0 & 1 & 0 & 0 & 0 & 0 & 1 & 1 & 0 & 0 & 1 & 0 \\
\hline 3.3
\end{tabular}

3.3 Solving the reachable matrix

According to the 13-order adjacency matrices to solve the reachable matrix,boolean algebra algorithms applied to solving the reachable matrix in the process, $\mathrm{I}$ is the identity matrix, $\mathrm{A} 1=$ $\mathrm{A}+\mathrm{I}$, When the $\mathrm{A} 1 \neq \mathrm{A} 2 \neq \cdots \cdots=\mathrm{Ar}-1=\mathrm{Ar}$ operation stops,Obtains $\mathrm{Ar}-1$ is the reachable matrix r.The reachable matrix $\mathrm{R}$ is obtained by Matlab7.0 operation,table 3 .

Table 3 reachable matrix $\mathrm{R}$

\begin{tabular}{cccccccccccccc}
\hline Factor & $\mathrm{S}_{1}$ & $\mathrm{~S}_{2}$ & $\mathrm{~S}_{3}$ & $\mathrm{~S}_{4}$ & $\mathrm{~S}_{5}$ & $\mathrm{~S}_{6}$ & $\mathrm{~S}_{7}$ & $\mathrm{~S}_{8}$ & $\mathrm{~S}_{9}$ & $\mathrm{~S}_{10}$ & $\mathrm{~S}_{11}$ & $\mathrm{~S}_{12}$ & $\mathrm{~S}_{13}$ \\
\hline $\mathrm{S}_{1}$ & 1 & 1 & 1 & 1 & 0 & 0 & 1 & 1 & 1 & 0 & 0 & 0 & 0 \\
$\mathrm{~S}_{2}$ & 1 & 1 & 1 & 1 & 0 & 0 & 1 & 1 & 1 & 0 & 0 & 0 & 0 \\
$\mathrm{~S}_{3}$ & 0 & 0 & 1 & 0 & 0 & 0 & 0 & 0 & 0 & 0 & 0 & 0 & 0 \\
$\mathrm{~S}_{4}$ & 1 & 1 & 1 & 1 & 0 & 0 & 1 & 1 & 1 & 0 & 0 & 0 & 0 \\
$\mathrm{~S}_{5}$ & 1 & 1 & 1 & 1 & 1 & 0 & 1 & 1 & 1 & 0 & 0 & 0 & 0 \\
$\mathrm{~S}_{6}$ & 1 & 1 & 1 & 1 & 0 & 1 & 1 & 1 & 1 & 0 & 0 & 1 & 1 \\
$\mathrm{~S}_{7}$ & 1 & 1 & 1 & 1 & 0 & 0 & 1 & 1 & 1 & 0 & 0 & 0 & 0 \\
$\mathrm{~S}_{8}$ & 1 & 1 & 1 & 1 & 0 & 0 & 1 & 1 & 1 & 0 & 0 & 0 & 0 \\
$\mathrm{~S}_{9}$ & 1 & 1 & 1 & 1 & 0 & 0 & 1 & 1 & 1 & 0 & 0 & 0 & 0 \\
$\mathrm{~S}_{10}$ & 1 & 1 & 1 & 1 & 0 & 0 & 1 & 1 & 1 & 1 & 0 & 0 & 0 \\
$\mathrm{~S}_{11}$ & 1 & 1 & 1 & 1 & 0 & 1 & 1 & 1 & 1 & 0 & 1 & 1 & 1 \\
$\mathrm{~S}_{12}$ & 1 & 1 & 1 & 1 & 0 & 1 & 1 & 1 & 1 & 0 & 0 & 1 & 1 \\
$\mathrm{~S}_{13}$ & 1 & 1 & 1 & 1 & 0 & 1 & 1 & 1 & 1 & 0 & 0 & 1 & 1 \\
\hline
\end{tabular}

$3.4 \quad$ Reachable matrix reordering

Sort of cut up the reachable matrix obtained skeleton matrix G, as shown in Table 4.

Table 4 skeleton matrix $\mathrm{G}$

\begin{tabular}{|c|c|c|c|c|c|c|}
\hline Factor & $\mathrm{S}_{1}+\mathrm{S}_{2}+\mathrm{S}_{4}+\mathrm{S}_{7}+\mathrm{S}_{8}+\mathrm{S}_{9}$ & $\mathrm{~S}_{3}$ & $\mathrm{~S}_{5}$ & $\mathrm{~S}_{6}+\mathrm{S}_{12}+\mathrm{S}_{13}$ & $\mathrm{~S}_{10}$ & $\mathrm{~S}_{11}$ \\
\hline $\mathrm{S}_{1}+\mathrm{S}_{2}+\mathrm{S}_{4}+\mathrm{S}_{7}+\mathrm{S}_{8}+\mathrm{S}_{9}$ & & 1 & & & & \\
\hline $\mathrm{S}_{3}$ & & & & & & \\
\hline $\mathrm{S}_{5}$ & 1 & & & & & \\
\hline $\mathrm{S}_{6}+\mathrm{S}_{12}+\mathrm{S}_{13}$ & 1 & & & & & \\
\hline $\mathrm{S}_{10}$ & 1 & & & 1 & & \\
\hline $\mathrm{S}_{11}$ & & & & & \\
\hline
\end{tabular}

Analysis of the active elements in the skeleton matrix, such as Table 5. 
Table 5

\begin{tabular}{|c|c|c|c|c|}
\hline $\begin{array}{c}\text { Level } \\
\text { number }\end{array}$ & $\begin{array}{c}\text { Reason priority } \\
\text { tiering }\end{array}$ & $\begin{array}{c}\text { Result priority } \\
\text { tiering }\end{array}$ & Common factor & $\begin{array}{c}\text { Activity } \\
\text { elements }\end{array}$ \\
\hline 0 & 3 & 3 & 3 & \\
\hline 1 & $1+2+4+7+8+9$ & $1+2+4+7+8+9$ & $1+2+4+7+8+9$ & \\
\hline 2 & $6+12+13$ & $5,6+12+13,10$ & $6+12+13$ & 5,10 \\
\hline 3 & $5,10,11$ & 11 & 11 & 5,10 \\
\hline
\end{tabular}

Calculated from the tables on elements of the activity and their activity level (Table 6):

Table 6

\begin{tabular}{|c|c|c|}
\hline Factor & Start level & End level \\
\hline 5 & 2 & 3 \\
\hline 10 & 2 & 3 \\
\hline
\end{tabular}

3.5 Drawing structure directed graph

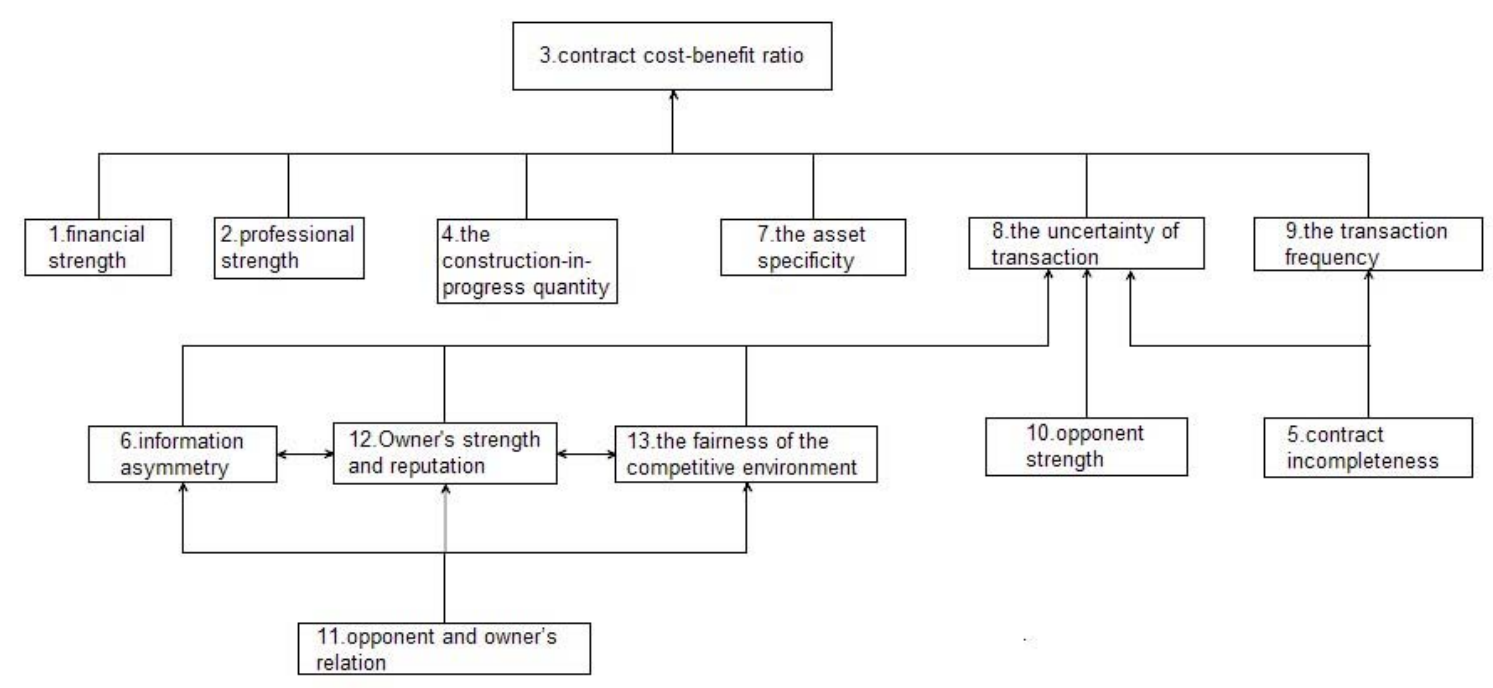

\section{Analysis and suggestion}

According to the transaction cost with Interpretative Structural Modeling Method (ISM) of the construction contract, the influence factors S1 S13 of the four aspects, the construction enterprise itself, the objective factor, the opponent factor, the environment factor, have hierarchical relationship each other.

The first one is the contract cost-benefit ratio as the top of the model, which is the most fundamental and important factor. In the contract transaction cost, the lower the ratio of the costs of the input and the output, the higher the benefit obtained. From economic perspective, the contract cost-benefit ratio can reflect the pros and cons for the result of project contract management. It is beneficial to optimize the allocation of resources. Meanwhile, it can provide reference for the similar contracts or sign contracts with the same employer.

Secondly, six impact factors ,the construction enterprise financial strength, the professional strength, the construction-in-progress quantity, the asset specificity, the transaction frequency, the uncertainty of the transaction, stay at the second level of the model with closely linked and are the key point of effecting the contract cost-benefit ratio. In order to improve the efficiency of construction contract transaction cost, it is need to increase the capital strength and professional strength of the construction enterprise firstly and to consider the impact of the construction-in-progress on the enterprise assets. The raise of the transactions frequency of the same employer and the intention to reach a transaction are also important ways to reduce the cost of construction contract.

Finally, the basic level factors: the information asymmetry, the owner's strength and 
reputation,the fairness of the competitive environment, the opponent strength, the contract incompleteness, influence to the uncertainty of transaction and the transaction frequency in different degree. At the same time, the information asymmetry, the strength of the owners, and the competition environment affect and restrict each other, the relationship between the opponent and the owners may have impacts on the competitive environment. The contract incompleteness as an objective factor have a joint effect to the transaction costs uncertainty and frequency. In many cases, the impact of external factors is not controlled, but before the construction contract being completed, the over-all environment and competitive environment can be fully investigated by the construction enterprise. It is unnecessary to reach a contract with excessive manpower and financial resources if the competition is too fierce or the owners tend to be too clear but low gains. The risks can be avoided partly, as long as the competitive environment can be understood clearly before reaching the contract transaction.

\section{Conclusion}

This article, standing in the construction enterprise angle, constructs the ISM method on the basis of influence factors of the contract transaction cost of large-scale construction items, analyses the lager affecting 13 factors to the cost, clears the link and the system rank orders of each factor. The contract cost-benefit ratio as the conclusion factor plays an dominant role in overall situation. The contract transaction cost controlling should be pay great attention when the construction enterprise carries on the large-scale construction items. Based on the combination of the relation of each factor, the model in this paper analyses controlling the enterprise and references for reducing the transaction cost of the construction contract.

\section{Acknowledgments}

This paper was supported by Fund Project—Soft Science of Shaanxi Province "large engineering construction project contract management present situation analysis and countermeasure research of Shaanxi" (2013KRM43)

\section{References}

[1]Li Changgu,Liu Zixian.A Study on Transaction Cost of Supply Chain Based on Signal Game[J].Science of Science and Management of S.\& T.,2005(9):133-137.

[2]NI De-bing,DAI Chun-ai,TANG Xiao-wo.Implici "Guanxi” and Explicit Incentive[J].,Journal of Industrial Engineering and Engineering Management2011,25(3):139-147.

[3]Sun Ying,Zhang Beibei,Huang Youliang.Analysis of the factors affecting the transaction cost of the energy service contract[J].Construction Economics,2011(7):13-16.

[4]Li Huimin.Analysis of factors affecting the transaction cost of construction project[J].Project management technology,2012,10(8):35-39.

[5]Chris M Wilson,Luke Garrod, Alistair Munro.Default effects, transaction costs, and imperfect information[J].Economics Letters,2013,119(5):213-215.

[6]Queena K Qian,Edwin H.W. Chan,Lennon H.T. Choy.How transaction costs affect real estate developers entering into the building energy efficiency (BEE) market[J].Habitat International,2012,37(1):138-147.

[7]Ke Hong,Lv Tingzhu,Du Yaling.Measurement Research on the Incompleteness of Project Contract Based on SEM[J].Journal of Beijing Institute of Technology (Social Sciences Edition) ,2014,16(2):69-75. 